\title{
The Construction of Cultural and Gender Identity in Children, Adolescents and Young People
}

\author{
Belkis Luisa Aranda Cintra ${ }^{1}$, Mayelin Heredia Vega ${ }^{1}$, Yamilet Ávila Seco ${ }^{2}$, \\ Maria Antonia Henriquez Rodríguez ${ }^{3}$ \\ ${ }^{1}$ Pedagogical Research Center, Education Science Faculty, Oriente University, Santiago de Cuba, Cuba \\ ${ }^{2}$ Medical Statistic Department, Nurse Faculty, Oriente University, Santiago de Cuba, Cuba \\ ${ }^{3}$ Foreign Language Department, Education Science Faculty, Oriente University, Santiago de Cuba, Cuba
}

\section{Email address:}

belkisa@uo.edu.cu (B. L. A. Cintra),mherediav@uo.edu.cu (M. H. Vega), yavila@fts.scu.sld.cu (Y. Á. Seco), mariaalberto@nauta.cu (M. A. H. Rodríguez)

\section{To cite this article:}

Belkis Luisa Aranda Cintra, Mayelin Heredia Vega, Yamilet Ávila Seco, Maria Antonia Henriquez Rodríguez. The Construction of Cultural and Gender Identity in Children, Adolescents and Young People. International Journal of Education, Culture and Society.

Vol. 3, No. 3, 2018, pp. 42-48. doi: 10.11648/j.ijecs.20180303.11

Received: May 5, 2018; Accepted: June 14, 2018; Published: July 25, 2018

\begin{abstract}
The construction of cultural and gender identity in children, adolescents and young people takes the form of learning based on a broad cultural conception, taking into account all the opportunities of school life, not in learning limited to the passive and decontextualized transmission of information in the classes, with an insufficient use of the educational action of the educator. For a successful performance of new generations, since education in the various facets of life, is derived their preparation for love and conscious sexuality. Consequently, they develop responsible and enriching sexual relations with the couple properly selected to form, if so they want a stable and happy family that, in turn, exerts a beneficial influence on the happiness of society as a whole. In this article are based some considerations on the construction of the cultural and gender identity of children, adolescents and young people.
\end{abstract}

Keywords: Cultural Identity, Gender, Education, Sexuality, Adolescents

\section{Introduction}

The concepts of culture and gender have been the object of study of the modern social sciences conditioned by the global and multifaceted character that they reach in the current conditions, becoming the most important criteria for the development of the economic, political and spiritual life of society.

The construction of the cultural and gender identity has as its mechanism the significant learning, a process that integrates the assimilation, internalization and externalization of the different contents of the family and community school culture. An optimal development of the same is achieved by allowing the construction, resignification of the lived processes of each individual and the appropriation of a meaning and sense of the same.

Identity is built on the knowledge that children, adolescents and young people have of themselves and the world around them, of their abilities, of the discovery of what they can create and express, of everything that makes them similar and different, of others and the relationships they establish with others.

For Pozo, to build means to interpret and give meaning to a reality based on what is already known. Accept internal and deep relationships by penetrating their intimacy and putting it in relation to the cognitive structures that it already possesses; Approaching the object or content in order to learn it, based on previous experiences, interests and knowledge. [1]

The contructivists like Ausbel, D. (1980); Coll, C. (1970); Díaz, F. (1999) agree that construction exists when there is evidence of elaboration, selection, organization and transformation of the information received from different sources and previous knowledge, when what has been learned takes on meaning. [2]

The process of construction of cultural identity and gender 
in children, adolescents and young people becomes an educational need to preserve the values of our society by privileging the traditions of our people and their historical continuity. At these ages, development is appropriate to influence educational practices that consolidate socially established personality qualities. [3]

This process must be organized around the need to achieve a coherence of the influences of all the civic communities where it is inserted, bearing in mind that the family is the first initiator of this training and is the continuation school of this process, for its social function, organization, planning of the contents of culture and science in the different subjects and for being a basic institution of society for the education of the new generations, therefore, it must strengthen its role as guidance to the family and the different institutions of the community in favor of the conservation and renovation of the daily practices of customs, traditions, heritage.

Sexuality is constituted throughout life, but it has its sensitive periods in childhood, in early and late adolescence, in the process of general and sexual education in particular, through the formal channels of the educational system. The sense, the aims, the aspirations, the forms of expression and realization of the sexuality of each human being, is acquired through the formative influence of the family, the educational instructions and all the social forces as a whole. The human being must learn, from the most tender ages, to be sexed, to become a male or female individual that from his conception as a fetus will transfer from birth to death by various stages in which he will experience and express a way or other needs, motivations, sexual interests, which will be manifested through certain behaviors that must be understood and effectively oriented by the persons in charge of their education. This article synthesizes general reflections about the construction of the cultural and gender identity of children, adolescents and young people, as concrete alternatives that favor the preparation of all the agents and socializing agencies that intervene in this process. There are new challenges to take into account in the training purpose of these.

\section{Methods}

A qualitative and descriptive study of children, adolescents and young people's formation process was made in Santiago de Cuba province in Cuba, since 2016. The sample was carefully selected through a simple aleatory sampling with a stratified selection comprising the general population in subpopulation. In a population of 120 children from $2^{\text {nd }}$ grade of a Primary School were selected 20 children representing $16.6 \%$. From 120 adolescents of $8^{\text {th }}$ grade from a Junior High School, were selected 25 adolescents, representing 20\% and from Psychology and Pedagogy major, 50 young people were selected from 103 , representing $48.54 \%$.

In order of fulfill the objective proposed, the following indicators were established:

a) Learning practice implication of different contents and its expressions in children, adolescents and young people manifestation in dissimilar behavior acting.

b) Identification of the behavior expressions of male and female linked with family culture, community and nation.

c) Fittingness in groups where is settled the family, community and nation.

It was a need to use methods and instruments such as interviews, quiz, problem inventory and observation of children, adolescents and young people in different framework.

\section{Results}

In a $97.9 \%$ of children, adolescents and young people appear behaviors linked with the culture of their framework but they are more emphatic in art manifestation. In a general scope, autochthon, traditions, habits and myths are heritage that identify them.

The results revels that children, adolescents and young people arrived to their first psychosexual experiences due to physique changes, biological and social matureness and the new social situation. Their needs, impulse and desire compose new feelings that crystallize in the other sex attraction starting couple love relation, physical attraction, erotic exchanges. In the other hand, from the social scope frequently they do not know how to react due to a lack of information and orientation about how to behave, act and solve the increasing sexual impulse. It is the time in which they could face an established social model that allow sex opposite relations but prohibit couple relation with the same sex.

In a 97.9\% children, adolescents and young people said that they need to acquire more information and deep in knowledge about sexuality that could orientate them early in sexuality and sex orientation but they consider that diversity in sexuality is being respected. They recognize that not always is possible to be happy when they have a different sex orientation.

In general, young have stable couple relations, establishing sexual orientation and new families appear in which they play an active role as father.

\section{Discussion}

The culture of each region and country includes a series of ideas, values and models of behavior with which all members of society must be familiar. In this interpretation of culture, behavior and behavior are given a series of responses in a particular situation, the qualification of the configuration model, integrated by the content and organization that it possesses, which acquires great importance for studies of children, adolescents and young people From this position it is considered that culture is all the content that people gradually acquire in the process of socialization, relating the processes of human, spiritual, material, intellectual and emotional creation that integrate values system, way of life, beliefs, traditions, customs, languages, technologies, contents 
of the sciences, institutions, patrimonies and the art that characterizes society.

Through culture, man expresses himself, becomes aware of himself, questions his accomplishments, looks for new meanings and creates works that transcend and that identify him culturally, conforming and expressing his cultural identity.

It is in favor that the existence of the spiritual life should not be approached in the abstract, but always circumscribed historically; hence the methodological value of the socioeconomic formation concept for the analysis of the spiritual life, distinguishing above all its class character. The development process of each child must be carried out in a contextualized way, knowing the individual history of its development, the concrete conditions of its environment, the dynamics that it produces and its time, this makes its cultural development have its particularities, its specific conditions that makes it different and different, achieving in this relationship the necessary differentiation between the innate and the cultural, the natural and the historical, the biological and the social. For its part, the identity has been treated in various ways by numerous sciences and researchers naming it firm sense of group identification; search for meaning, the process of constructing meaning, the need for existential maintenance and universal integration; rooting framework; need to know ourselves and self-fulfill; the need to know oneself and be recognized, the need for a sense of belonging and a positive self-concept; basic needs for selfdetermination; protection and dignity: individual and social need for continuity between the past, present and future, and many other aspects. In this regard the Cuban doctor de la Torre C. raises: "call it what you call the same is emphasized in reflexivity, the search for meaning, self-esteem, freedom or belonging, people seem to continue needing that feeling of relative subjective continuity and harmony provided by the personal identity and also the feeling and awareness of belonging to certain human groups [4] This corroborates the importance of the need to continue studying everything related to the construction of personal and cultural identity from the first moments of the life of the human being, as the only way to achieve feelings of belonging and defense of the entire legacy of the family, community culture, of the nation and of the universal. The problem of identity in its sociocultural significance has regained its singular importance and relevance, this being one of the most difficult and complex tasks presented by the social and humanistic sciences. Taking this meaning into account, the Cuban doctor García A. recently stated: "By identity we understand the set of qualities, characteristics and experiences, signs and situations of the social environment that allow a subject to differentiate a particular individual or a specific social group. Thus we could define a personal identity, referred to each individual in particular, and a social identity, referred to a specific human group. [5] This quality of identity, its simultaneous link with equality and difference that in one way or another are always present in any act of identification, whether externally establishing the identity of a thing or person, the person associates or identifies with another thing or person.

The authors of this work deepen in the marked differentiation that exists between people based on the elements that identify it, this leads us to consider that identity is the feeling of belonging of emotional, historical, cultural, ethnic closeness that is part of a determined group characterized by -0ññts moral values, daily life, customs, traditions and authentic heritage that distinguishes it from others. Personal identity is the set of characteristics, modes of individual behavior and system of moral values morals that the individual develops in the course of life, from their experiences, experiences, reflections and authentic appropriation of the distinctive features of the groups of belonging. The construction and development of personal identity and its social projection implies self-recognition or knowledge of a set of qualities that typify a person, group, nation and continent. The psychoanalyst Erikson, E., in his book "Childhood and Society" raises in one of his first definitions: "At this point suffice to say that this feeling of identity allows to experience the self as something that has continuity and sameness, and act accordingly. [6]

He does not refer only to the objective and subjective evidence of being an individual entity or part of a social group; but it pre-empts the importance of identity as a sense of belonging and regular elements of behavior, in motivations, feelings, values, prejudices and attitudes, more or less continuous, which must be expressed in actions that are consistent with them. When talking about social identities, it refers to an internal solidarity, feelings of belonging, identification with the ideals of the group.

Thus, cultural identity is understood as the awareness of the uniqueness of qualities similar to those preserved and renewed in the heritage environment, assimilated by the historical social experience inherited from humanity, acquired by the educational action of the family, the school, the different institutions and groups, as well as the potential to drive their development.

In turn, identity in early childhood is the identity of the man who recognizes himself in his most immediate community. And identity is the set of historical values, strictly cultural values in the full and broad sense of the term and strictly artistic values. These observations indicate that identity is integrated by the set of values that make up the individual's social status and that represent it, distinguish it at a given time, and add an important element in the concept of identity when declaring that man recognizes in its most immediate community, understood as the social environment where the individual interacts, what is close to him and, therefore, facilitates his identification with the whole sociocultural process. The personal identity is formed and projected in the family and social group, its development is limited or grows according to the individual assimilation in the course of life, from the experiences of childhood, experiences and reflections of the youth when they can be integrated cultural and national identity, which are also inserted in the system of relations of a country with the rest of the world and its infinite interactions in all fields of 
science and human activity, therefore of their cultures. The beginning of reaffirmation is possible for the development of important psychological and identity processes that occur in the family group: communication through the word, (language), the role play where he imitates "models" of mother, father, figures with trades and professions, assimilation of patterns, moral values, customs of everyday life and generic identification, observing that some physiological needs are they solve differently. Being the family where the child is nourished by all the more general social values that shape the cultural identity of a country and the primary factor of conservation and transmission of the guidelines that confirm the patrimony of a society and guarantee the continuity of the culture, it is evident that this has undergone great social transformations that affect the individual subjectivity on a system of customs and traditions that has led to different family practices and the emergence of new values and models, considering this group not only in a relationship by consanguineous ties and conjugal, but also for reasons of affinity, necessity or strictly circumstantial. The family continues to show its integrating potential and its irreplaceable role of affective socialization, it is evident that the rapid technological and social change limits its possibilities of constituting a social cosmos model, as an institution, it is also fragmenting into different types, and none of them by itself is able to guide children in modern social relationships. There is also an inseparable relationship between personal development and community development because the first can not occur without the help of social and cultural conditions. On the other hand, the Cuban psychologist Tejeda, L., in her conception about identity, states that this depends to a large extent on the educational action of society and on the possibility of the individual to conduct his own development; for this reason, creativity is not a capacity of the human being, but is that which allows it to deploy, to the maximum, its potential for itself, its particular modes of appropriation of culture and, at the same time, expression of your inner universe through play, recreation, study or scientific, technical or artistic work. [7] Technical advances and the development of science in general do not have to imply loss of cultural identity, because both are compatible and necessary, in the same way the coexistence of modernity and tradition should not occur in such a way that one assimilates the other. Culture is assumed in a permanent evolution, in interconnection with hundreds of channels, we think of a cultural identity, not as a manipulation of forms of the past, nor as a formal resurrection of national styles, but as an inter-organization of what we were, we are and we will be; This is how the conservation of the autochthonous is understood so that it serves as a vital daily reference and becomes a true cultural identity.

The story collects in the specialized bibliography the word gender, which comes from the Latin "genus", which in English is called gender ". Its meaning is associated in dependence to its use and to the sociocultural assimilation of the context, which has allowed not to remain static in time, but to evolve together with social processes and tempering the current conditions of contemporaneity. In the 1980s, several studies of the subject are referred to highlight masculine and feminine roles, specifically not determined by biological characteristics, but by cultural, social and economic situations, basing the cultural base of gender relations and determining that society defines it by the activities, the status, the characteristics and the forms of behavior of each one of the types of genres.

The sociocultural formation of the subjects allows without being absolute to configure the bases of sexuality, which in turn is historically defined by the generic order. It is a symbolic construction that integrates the attributes assigned to people based on their sex. [8] Thinking about the gender category implies: thinking about the important actions that characterize and systematize subjects throughout life, activities, creations, doing in the world, intellectuality and affectivity, language, conceptions, imaginary, fantasies, the desires, the identity, corporal and subjective self-perception, the sense of oneself, and its recognition of uniqueness, the material and symbolic goods, the vital resources, the power of the subject, the capacity to live, the social position, hierarchy, status, relationship with others, opportunities and limits of each, the meaning and meaning that life takes.

The generic social study is the result of establishing sex as a brand to assign specific activities, relationships and recognitions to each person.

Human sexuality is socially resignified and expressed in a gender order that distinguishes the masculine - feminine, two ways of life, two types of subjects, two ways of being and existing, erotic, economic, social, cultural, psychological, different politicians marked by the social imaginary where each subject develops.

Specialists of the subject: sexologists, psychologists, doctors, sociologists, teachers assert that gender is not sex, a criterion that is shared in this work, considering that sex is determined by physical, biological, anatomical and physiological hereditary characteristics in human beings, they organize individuals into two categories; male and female, recognizing it from their genitals and sex, understood as a natural condition with which they are born. However, they emphasize that the construction of gender from the patriarchal ideology prevents this dialogue in diversity and democracy, but rather produces exclusion, dichotomies and oppression.

Therefore, the gender perspective implies a resignification of what up to now has been understood as male-female, male-female, private-public, maternity-paternity. The gender perspective includes the analysis of intergeneric and intrageneric relationships, private, public, group, collective, intimate and political that allow an analysis not only of society, its organization and institutions that are responsible for exercising consensus and social coercion in this sense they categorize the subjects in a certain type of gender.

The understanding of the gender category is also analyzed from this perspective, because the individual and collective experiences that originate the duties and obligations allow the expression of the norm and with it the reproduction of the gender order, which behaves behaviorally in social life. 
The analysis carried out by several researchers who study the subject points out that the gender perspective implies an ethical view of development and democracy in order to face inequality, inequality and gender oppression, such as a critical position and a proposal of alternatives for the change.

Each geographical region, country, society, people, group and human being possesses a conception of gender based on their own culture. It is part of the vision of the world, of national and popular traditions, community, generational, family and its history. Each individual has an individual subjective expression that sensitizes all the historical and sociocultural evolution in which we have actively interacted. For the understanding of this it is necessary to take into account the elements corresponding to the integration of the individual subjectivity itself (motivations, needs, psychodynamic processes, experiences, self-acceptance, selfdetermination, self-assessment processes, worldviews, life scripts, myths).

The above arguments allow to affirm that the term gender has a strong social base, which starts from the supposed biological differences between the sexes. It refers to roles, responsibilities, rights, relationships and cultural and gender identities of men and women, which are defined or attributed within a society and context where the subjects are located and in acceptance by the social imaginary.

The sociocultural intervenes creating different identities for each of the sexes. These identities (cultural, social, psychological, political, legal and economic) determine how the social behavior of women and men should be, as well as the relationship established between them.

The assimilation of the activities, social relations, forms of behavior and moral, civic and civic norms that in each era, society, culture, are the specific contents of being a man and being a woman, allow establishing the differentiation of identity, designating its functions, aspects that allow us to continue corroborating that gender is a social construction that depends to a great extent on a specific context, on its culture, classes and concrete socio-historical conditions where people, family, school institutions, community and groups where they are inserted are formed.

The authors assume family as a determining institution in the cultural identity and specifically the gender identity since from the conception of the egg or zygote with the union of the sperm and the ovum in the womb of the mother, once known by the parents, it begins to build the ideal child or girl you want to have, the assigned gender affects the expectations and the way in which the newborns are perceived. [9]

What do the parents, family and friends of a baby expect when they reach adulthood depending on their sexual identity if it is female or male?

If this is sometimes not accepted to be verified with medical tests that are made to the mother from the intrauterine life must be recognized and accepted by both parents to enrumber the communication and interpersonal relationships accepted by each type of gender.

Gender identity is elaborated internally from stereotyped beliefs derived from a psychic activity generated from social influences.

"Gender identity in children, adolescents and young people covers the set of processes that enables the conceptualization of oneself as a male or as a woman (...) the identity process is constructed in close harmony with biological sex, so that normally a male, his personal identity is constructed by identifying himself with the group of males and a woman with the group of women. Barbera, E. (...) is the process by which everyone knows they belong to a group of sexual assignment and excluded from the other (...). "Idem, expressing itself in a whole range of subjective processes. [10]

In our opinion, the construction of gender in children, adolescents and young people is a multifactorial process assigned by the experiential, acquired and assumed by the subjects in the training and guided by essential aspects such as:

a) The education received by children, adolescents and young people in socializing contexts should make them competent in the society in which they live, by their moral formation, by the fulfillment of their duties and the enjoyment of their rights, by their citizen participation and commitment to the social ideals, thus influencing civic and civic education.

b) The set of typical forms of life activity carried out daily by members of the family, the relationships established between themselves and their environment, should favor the appropriation of certain objective and subjective living conditions in a context sociocultural determined.

c) In the set of activities and social relationships that take place in a specific time, rhythm and space, they must foster thought and feeling action individually and collectively that allows the interpretation of the individual and the social in practice, which distinguishes their sexuality in a specific context.

d) The interpersonal relationships that are manifested in the complex network of links and interactions that are established between members of different ages and friends close to the family; norms and behaviors must emerge based on the feelings, emotions and affections generated by the participants in these relationships based on the particularities of the joint activity in which the subjects are involved and organize the plot of daily life that corresponds to an adequate gender identity.

e) The system of affective bonds that are superimposed beyond coexistence, where the relationship between mother (s), father (s), siblings and other relatives are the real components of the system, gender models are also included adequate, associated by kinship in a permanent legacy of norms, values and modes of behavior that move from one generation to another establishing the necessary identification and differentiation depending on the sex and the context where it is located. 
f) The roles included as the set of functions performed by children, adolescents and young people to occupy a certain position and interaction in their family, school and community must embody the interpersonal and social relationships that are established and translate into the fulfillment of concrete social norms, centered around the position that is occupied in each one of the groups in which it is inserted typifying the established gender that identifies it.

g) The rules that are established must become rules established by the family that comes from society, determined by the stable forms of social interaction of its members that are transmitted from generation to generation and that are updated in light of the new social demands directed to the reach of new family goals. The norms are deployed in the different contexts of action through the daily social behavior in children, adolescents and young people and the actions that are socially significant for him must be patterns to follow daily.

h) The values constituted by the system of patterns commonly accepted in the family through which children, adolescents and young people correlate and mediate their interactions with the rest of the family group and with society in general in their training must assume models and comply with standards handed down by the generational existence, but which are not statified nor do they act as radical ruptures with respect to the previous unit, which does not imply an exact repetition of the preceding patterns due to the differential impact of the socializing contexts and the system of relationships offered by social continuity, but the correct behavioral educational character must prevail.

i) The psychological spaces must be respected as soon as their location is established, a system of interactions and relationships is determined that by a certain interplay of assignments and assumptions of roles inside and outside the groups that widen and change as they are constructing certain meanings endowed with objective feasibility, through a subjective process that favor the negotiations of limits that determine the personal space allow the construction of the identity.

j) The limits are revealed in the system of facets that are established between children, adolescents and young people and the rest of the system of which it is a part, marking the limit of their behavior and facilitating the appearance of others. In each system of relationships and interrelations, these facets are integrated differently in the attributes of the potentialities of their sexual identity, so that these sequences of behaviors can be exclusive and respected in context or given time to be accepted socially.

k) Guidelines must be established to determine who, how and when a particular action is carried out that corresponds to a stable behavior of gender identity, which facilitate and coordinate its operation and are essential for every child, adolescent and youth know how to behave.

1) The educational treatment of gender based on experiences, personal history, the contradictions between what is assigned and what is assumed, what is wanted and what can not be achieved and what is unattainable, personal and social, and the particular of gender and the singularity of the existing forms of gender must be coherent among all the influences of the educational system that children, adolescents and young people receive.

The construction of gender identity appears in interaction with the learning of gender roles and typified behaviors. Gender stereotypes refer to beliefs, expectations, causal attributions that are thought and shared by certain groups (male-male and female-female).

\section{Conclusions}

The construction of cultural identity and gender is conceived from the process the sociocultural dimension in the comprehensive education of children, adolescents and young people which is possible when they are able to assume a behavior and behavioral manifestations that identify it with their traditions, customs, beliefs and values settled from generation to generation in the family, the community and their nation.

The sociocultural aspect of the construction of the cultural and gender identity of children, adolescents and young people is configured in a system of relationships whose essential dynamic is established from the present to the past and projected into the future in the various socializing contexts where are located.

Gender in its condition and category of feminine or masculine is constituted in a series of historical characteristics that define in a determined society what a woman and a man should be. It is something involuntary, it is therefore a socio-historical condition, comprising social and cultural aspects that are determined by society as a whole and that are inherent to women and men, promoting from a young age a reflective position of learning for the solution of personal and social problems, addressed in family and social life, that stimulates the metacognitive activity of children, adolescents and young people, that guide their conscious regulation and subjectivize the daily family experience, turning them into protagonists of the facts of their culture.

\section{References}

[1] Pozo, J. (1991). Teorías cognitivas del aprendizaje. Editorial Morata. Madrid. España. p 13

[2] Ausubel, D. (1980). Psicología educativa. Un punto de vista cognoscitivo. Editorial Trillas. México.p .21

[3] Aranda Cintra, Belkis L. (2004). Communication: a necessary process in the formation of the cultural identity of schoolchildren. In Minutes of the IX Symposium International of Social Communication. Santiago de Cuba. Cuba. p.32 
[4] de la Torre Molina. C. (2004). Las identidades individuales y colectivas. Centros de investigación y Desarrollo de la Cultura Cubana Juan Marinelo. La Habana. Cuba. p.26

[5] García Morey A. (2000). La identidad cultural y social en el niño. Editorial Pueblo y Educación. La Habana. Cuba. p. 46

[6] Erikson E. (1900) Infancia y sociedad. Paidós. Editorial Hoomé. Buenos Aires. Argentina. p.26

[7] Tejeda Lecsy. (1991). Identidad cultura y desarrollo moral en algunos creadores y una muestra de población de Cuba. Tesis para doctorado de Ciencias Psicológicas. Universidad de la Habana. La Habana. Cuba. 62h
[8] El proceso de comunicación exigencia básica en la orientación sociocultural del niño ISBN 978_959_7174_30_1 (Libro volumen II) en el XIV Simposio Internacional de Comunicación Social; 2015 (Libro)

[9] Aranda B. L. (2005) Metodología para la formación de la identidad cultural en escolares primarios. Tesis en opción al grado científico de Doctor en Ciencias Pedagógicas. Universidad de Ciencias Pedagógicas. Santiago de Cuba. Cuba.

[10] Wundt, W.: Compendio de Psicología, La España Moderna, Madrid. p.28 